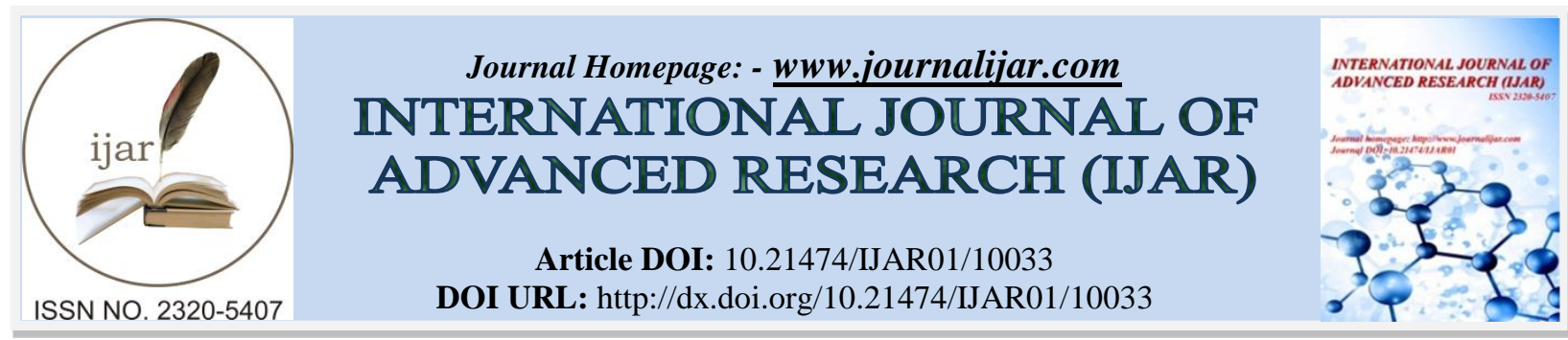

RESEARCH ARTICLE

\title{
ISOLATION, IDENTIFICATION AND SCREENING OF HALOPHILIC BACTERIA FOR POLYHYDROXYALKANOATE (PHA) IN HYPERSALINE LAGOS WATER BODY, NIGERIA.
}

\section{Fayemi, Scott $\mathrm{O}^{1}$, Boboye Bolatito ${ }^{2}$ and Olukunle Oluwatoyin $\mathrm{F}^{3}$.}

1. Redeemer's University, Department of Biological Sciences, Faculty of Natural Sciences, PMB 230, Ede, Osun State, Nigeria.

2. Federal University of Technology, Akure (FUTA), Department of Biotechnology, PMB 704, Akure, Ondo State, Nigeria.

\section{Manuscript Info}

\section{Manuscript History}

Received: 10 September 2019

Final Accepted: 12 October 2019

Published: November 2019

\section{Key words:-}

Halophilic bacteria, Hypersaline water, Polyhydroxyalkanoate, PHA producing bacteria, Physicochemical characteristics, Phenotypic characterization.

\section{Abstract}

This study aims to identify bacteria associated with hypersaline water body in Lagos State, Nigeria, screen them for their potential to produce polyhydroxyalkanoates (PHA) and determine the physicochemical properties of the water. Enumeration, identification and testing for growth at $3 \% \mathrm{w} / \mathrm{v} \mathrm{NaCl}$ were carried out using standard microbiological techniques. Screening for PHA production potential of the bacteria was carried out using Sudan Black B staining techniques. Physicochemical analysis of the water (at depths of $0-0.07 \mathrm{~m}, 50 \mathrm{~m}$ and $100 \mathrm{~m}$ ) was determined using the methods of Association of Official Analytical Chemists. The highest and lowest bacterial loads of $20.66 \pm$ $0.47 \mathrm{Cfu} / \mathrm{mL}$ and $10.00 \pm 0.82 \mathrm{Cfu} / \mathrm{mL}$ were obtained from depth $50 \mathrm{~m}$ respectively. Eighteen (18) bacteria namely Micrococcus varians, M. luteus, Bacillus badius, B. macquariensis, B. megaterium, Corynebacterium kutsceri, Mycobacterium delbrueckii, Mycobacterium smegmatis, Staphylococcus aureus, Staphylococcus saprophyticus, Staphylococcus epidermidis, Lactobacillus delbrueckii, Klebsiella pneumoniae subsp. pneumoniae, Neisseria veillonella, Enterobacter intermedius, Enterobacter amnigenus, Serratia marcescens and Yersinia pestis were phenotypically identified from this study using Bergey's Manual of Systematic Bacteriology. The test for growth at 3\% w/v $\mathrm{NaCl}$ revealed that Bacillus badius had the highest optical density (OD) (2.84) at 520nm, while Serratia mercescens had the lowest OD (2.61) at $520 \mathrm{~nm}$. The physicochemical parameters of the hypersaline water ranged from 0.17 to $37.4 \mathrm{NTU}, 37300$ to $43500 \mu \mathrm{S} / \mathrm{cm}$ and 10 to $130 \mathrm{mg} / \mathrm{mL}$ for turbidity, conductivity and alkalinity respectively. The values obtained for Dissolved Oxygen, Chemical Oxygen Demand and Biochemical Oxygen Demand ranged from 4.08 to $4.42 \mathrm{mg} / \mathrm{L}, 4.21$ to $3699 \mathrm{mg} / \mathrm{L}$ and 4.21 to $924.75 \mathrm{mg} / \mathrm{L}$ respectively. Findings from this study revealed that $88.1 \%$ of the bacteria tested positive to PHA production and the presence of PHA producing bacteria has been established in the hypersaline water body of Lagos State, Nigeria.

Copy Right, IJAR, 2019,. All rights reserved. 


\section{Introduction:-}

\section{Halophilic bacteria as an extremophile}

Halophilic bacteria are extremophiles that live or survive harsh environments (Zhang et al., 2015) characterized by saltiness, they either tolerate certain salt concentration range or require it for growth. High salt concentration is one of the area factors that determine or limit the biodiversity of microorganisms. High salts water bodies otherwise known as hypersaline environment (e.g. marine water bodies). Hypersalinity in water bodies are associated by low oxygen concentrations (depending on the geographical area), high or low temperatures and are most times highly alkaline (Ollivier et al., 1994).

Halophiles are categorized into four, which are non-halophilic organisms, slight halophiles, moderate halophiles and extreme halophiles (Kushner, 1978). Non-halophilic is that organism that requires less than $1 \%$ (w/v) $\mathrm{NaCl}$ for their growth, but despite the fact that this group of microbes do not need high salt concentration for their optimal growth, they may tolerate it and so, they are considered as halotolerant microorganisms (de Lourdes et al., 2013). With respect to halophilic microorganisms, slight halophiles (for example, marine bacteria) grow best in media with $1 \%$ to $6 \%(\mathrm{w} / \mathrm{v}) \mathrm{NaCl}$, whereas the optimal salt concentrations for moderate halophiles range between $7 \%$ and $15 \%$ $\mathrm{NaCl}$; on the other hand, extreme halophiles show optimal growth in media containing $15 \%$ to $30 \%$ (w/v) $\mathrm{NaCl}$ (Madigan and Martinko, 2006; Manikandan and Senthilkumar, 2017).

The biomolecules such as polyhydroxyalkanoate (PHA) produced by halophilic microbes are stable due to their ability to live under extreme conditions (Oren, 2013; Parthasarathi et al., 2013; Santini and Warren, 2015).

Polyhydroxyalkanoates (PHAs) are biopolymers and may be produced by bacteria in order to overcome environmental stresses that are characteristic of hypersalinity. The vast attention towards PHAs is mainly attributed to its properties that resemble some petrochemical plastics, as well as its biocompatibility and complete biodegradability. Microbial activity in the natural environment breaks down such bioplastics to release carbon dioxide and water or methane under aerobic and anaerobic conditions (Naik et al., 2008). PHAs are biodegradable and of immense importance in the applications of medicine, engineering, agriculture, telecommunications, transportation and household utilities (Aditi et al., 2015; Zhang et al., 2015; Manikandan and Senthilkumar, 2017). They are inevitably important as components of production for razors, utensils, diapers, feminine hygiene products, cosmetics containers, shampoo bottles and so on. PHAs can be incorporated into packaging components such as coatings, laminations and biodegradable printing inks (Reddy et al., 2003; Mojaveryazdia and Rezaniac, 2013). PHA structures include rigid thermoplastics, thermoplastic elastomers and grades useful in waxes, adhesives and binders. Properties range from elastomeric to resins as stiff as nylon 6 or polycarbonate (Hall, 1981; Board, 2004; Olabisi and Adewale, 2016). Information gathered on PHA's producing bacteria ( DasSarma et al., 2010; Saranya and Shenbagarathai, 2011; Chao, et al., 2013; Saharan et al., 2014) revealed that little or no information has been found on the water bodies of Nigeria. It is therefore imperative to investigate the types of halophilic bacteria and their PHA producing potentials in Nigerian water bodies.

\section{Materials and methods:-}

\section{Collection of water samples}

Marine water samples of three (3) replicates from each location of Lagos State, Nigeria Southern Atlantic Ocean water body were collected aseptically with the aid of a water sampler using the modified methods of water sampling by Bugnicourt et al., (2014). The water samples were collected at three different depths (surface: 0-0.07m, middle: 50 meters and bottom: 100 meters below water surface) into a 1 litre separate sterile plastic container. The locations considered for the depths of the water collection were recorded from the Geographic Positioning System (GPS) as (1) latitude $6.35^{\circ} \mathrm{N}$ longitude $3.28^{\circ} \mathrm{E}(\mathrm{ST} 1)$; 2) latitude $6.35^{\circ} \mathrm{N}$ longitude $3.40^{\circ} \mathrm{E}$ (ST2); and 3) latitude $6.36^{\circ} \mathrm{N}$ longitude $3.47^{\circ} \mathrm{E}$ (ST3). The temperatures of the collected water samples were recorded in situ.

\section{Enumeration, isolation and identification of bacterial isolates}

The sampled water was serially diluted from $10^{-1}$ to $10^{-7}$, cultured by spread plate method on plate count agar (PCA) and incubated at $35^{\circ} \mathrm{C}$ for 24 to 48 hours. The colonies were counted.

Bacteria were characterized based on cultural characteristics which are; margins, elevation, growth shape.

The methods of Holt (1994) were employed for the morphological characteristics of the cells and these includes gram stain reaction, cells spore, acid fast staining reaction, cell shape and cellular arrangements. The biochemical assays in order to determine the absence/presence of catalase, oxidase; citrate utilization, nitrate reduction, the probe 
of the bacteria to determine if it is a strict anaerobe or not, the ability to hydrolyze starch. Also, included are assays to determine sugar fermentation ability, Vogues Prokauer (VP) and ability to grow in $6.5 \%$ sodium chloride. At the end of the assays on each of the isolates, each organism was identified with the Bergey's Manual of Systematic Bacteriology as utilized by Tissari, et al. (2010).

\section{Determination of the effects of $3 \%(\mathrm{w} / \mathrm{v}) \mathrm{NaCl}$ salt concentration on bacterial isolates}

Minimal salt medium (MSM) was prepared with the following constituents: $\mathrm{K}_{2} \mathrm{HPO}_{4}(0.5 \mathrm{~g} / \mathrm{L}), \mathrm{KH}_{2} \mathrm{PO}_{4}(0.04 \mathrm{~g} / \mathrm{L})$, $\mathrm{MgSO}_{4}(0.05 \mathrm{~g} / \mathrm{L})$, Ammonium dihydrogen phosphate $(0.04 \mathrm{~g} / \mathrm{L})$, Ferrous sulphate $(0.001 \mathrm{~g} / \mathrm{L})$, glucose $(8 \% \mathrm{w} / \mathrm{v})$ and $\mathrm{NaCl}(3 \% \mathrm{w} / \mathrm{v})$. The medium was sterilized in the autoclave at $121^{\circ} \mathrm{C}$ for 15 minutes at $15 \mathrm{psi}$, allowed to cool in the respective distributed test tubes, after which inoculation of pure isolates at $1 \times 10^{4}$ cell per $\mathrm{mL}$ was carried out aseptically, then subsequently incubated at $37^{\circ} \mathrm{C}$ for 2 to 72 hours before absorbance was taken at $520 \mathrm{~nm}$ with the aid of Spectrophotometer.

\section{Physicochemical analysis of water samples}

Physical, chemical and trace/heavy metal analyses were conducted on the marine water samples according to Bugnicourt, et al. (2014). The physical parameters temperature, pH, turbidity, conductivity and total suspended solids were studied according to Galinha, et al., (2018). The chemical parameter total acidity, total alkalinity, chloride by titrimetric method, nitrate, sulphate were also determined with the aid of spectrophotometry methods (Germer et al., 2014). Dissolved oxygen and chemical oxygen demand were determined by Ibtisam and Karim, (2012) methods, while biological oxygen demand were determined according to Kosseva and Web, (2013) methods.

\section{Assay for PHA Production}

Each bacterial isolate was grown in $100 \mathrm{~mL}$ minimal salt medium supplemented with $8 \%$ (w/v) glucose in a $250 \mathrm{~mL}$ conical flask and incubated for $37{ }^{\circ} \mathrm{C}$ for 72 hours $100 \mathrm{rpm}$ in an incubator. Thereafter, PHA production was investigated using Sudan Black B staining methods (Khanna and Srivastava, 2005). Data were recorded based on the positive observation of black colouration of the cells and negative observation of pink coloration of the cells.

All numerical data were subjected to statistical analysis using versions of IBM SPSS 2.0 and Microsoft Excel 2010 software.

\section{Results:-}

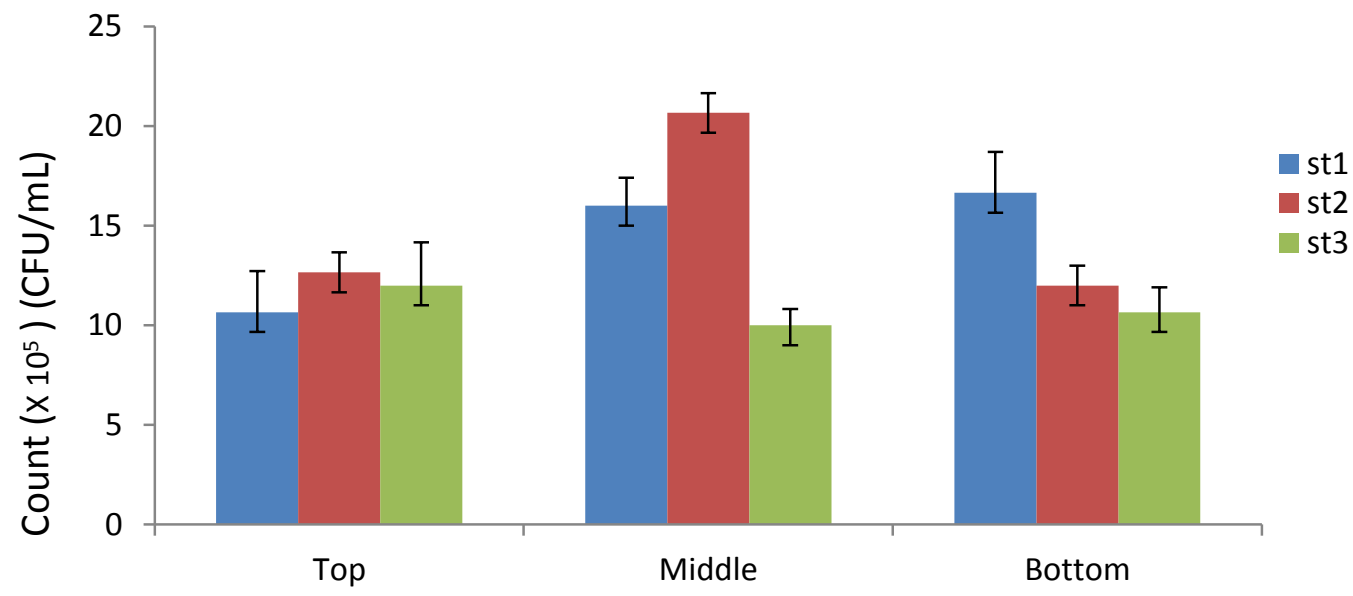

Location of hypersaine sample in water body

Figure 4.1:-Bacterial load of hypersaline water body in Lagos, Nigeria Legend.

St1 = latitude $6.35^{\circ} \mathrm{N}$ longitude $3.28^{\circ} \mathrm{E} ; \mathrm{St} 2=$ latitude $6.35^{\circ} \mathrm{N}$ longitude $3.40^{\circ} \mathrm{E} ; \mathrm{St} 3=$ latitude $6.36^{\circ} \mathrm{N}$ longitude $3.47^{\circ} \mathrm{E} ;$ Top $=0.07 \mathrm{~m}$ water surface; Middle $=50 \mathrm{~m}$ below water surface; Bottom $=100 \mathrm{~m}$ below water surface

\begin{tabular}{|l|l|l|l|l|l|l|l|l|l|l|l|l|l|l|l|l|l|}
\hline $\begin{array}{l}\text { Charact } \\
\text { ers }\end{array}$ & & & & & & & & & & & & & & & & & \\
\hline
\end{tabular}




\begin{tabular}{|c|c|c|c|c|c|c|c|c|c|c|c|c|c|c|c|c|c|c|}
\hline & 1 & 2 & 3 & 4 & 5 & 6 & 7 & 8 & 9 & 10 & 11 & 12 & 13 & 14 & 15 & 16 & 17 & 18 \\
\hline $\begin{array}{l}\text { Configu } \\
\text { ration }\end{array}$ & $\begin{array}{l}\text { rou } \\
\text { nd }\end{array}$ & $\begin{array}{l}\text { rou } \\
\text { nd }\end{array}$ & $\begin{array}{l}\text { rou } \\
\text { nd }\end{array}$ & $\begin{array}{l}\text { rou } \\
\text { nd }\end{array}$ & $\begin{array}{l}\text { rhiz } \\
\text { oid }\end{array}$ & $\begin{array}{l}\text { wrin } \\
\text { kle }\end{array}$ & $\begin{array}{l}\text { rou } \\
\text { nd }\end{array}$ & $\begin{array}{l}\text { rou } \\
\text { nd }\end{array}$ & $\begin{array}{l}\text { rou } \\
\text { nd }\end{array}$ & $\begin{array}{l}\text { rou } \\
\text { nd }\end{array}$ & $\begin{array}{l}\text { wri } \\
\text { nkle }\end{array}$ & $\begin{array}{l}\text { rou } \\
\text { nd }\end{array}$ & $\begin{array}{l}\text { wri } \\
\text { nkle }\end{array}$ & $\begin{array}{l}\text { rou } \\
\text { nd }\end{array}$ & $\begin{array}{l}\text { rou } \\
\text { nd }\end{array}$ & $\begin{array}{l}\text { wrin } \\
\text { kle }\end{array}$ & $\begin{array}{l}\text { rou } \\
\text { nd }\end{array}$ & $\begin{array}{l}\text { wri } \\
\text { nkle }\end{array}$ \\
\hline Margin & $\begin{array}{l}\text { wa } \\
\text { vy }\end{array}$ & $\begin{array}{l}\text { smo } \\
\text { oth }\end{array}$ & $\begin{array}{l}\text { wa } \\
\text { vy }\end{array}$ & $\begin{array}{l}\text { wa } \\
\text { vy }\end{array}$ & $\begin{array}{l}\text { wo } \\
\text { oly }\end{array}$ & $\begin{array}{l}\text { irreg } \\
\text { ular }\end{array}$ & $\begin{array}{l}\text { mar } \\
\text { gin }\end{array}$ & $\begin{array}{l}\text { mar } \\
\text { gin }\end{array}$ & $\begin{array}{l}\text { wa } \\
\text { vy }\end{array}$ & $\begin{array}{l}\text { smo } \\
\text { oth }\end{array}$ & $\begin{array}{l}\text { woo } \\
\text { ly }\end{array}$ & $\begin{array}{l}\text { smo } \\
\text { oth }\end{array}$ & $\begin{array}{l}\text { wav } \\
\mathrm{y}\end{array}$ & $\begin{array}{l}\text { smo } \\
\text { oth }\end{array}$ & $\begin{array}{l}\text { smo } \\
\text { oth }\end{array}$ & $\begin{array}{l}\text { irreg } \\
\text { ular }\end{array}$ & $\begin{array}{l}\text { wa } \\
\text { vy }\end{array}$ & $\begin{array}{l}\text { loba } \\
\text { te }\end{array}$ \\
\hline $\begin{array}{l}\text { Elevatio } \\
n\end{array}$ & flat & flat & $\begin{array}{l}\text { rai } \\
\text { sed }\end{array}$ & flat & flat & flat & $\begin{array}{l}\text { rais } \\
\text { ed }\end{array}$ & $\begin{array}{l}\text { rais } \\
\text { ed }\end{array}$ & flat & flat & flat & $\begin{array}{l}\text { rais } \\
\text { ed }\end{array}$ & $\begin{array}{l}\text { rais } \\
\text { ed }\end{array}$ & $\begin{array}{l}\text { dro } \\
\text { p- } \\
\text { like }\end{array}$ & flat & flat & $\begin{array}{l}\text { Rai } \\
\text { sed }\end{array}$ & $\begin{array}{l}\text { Rais } \\
\text { ed }\end{array}$ \\
\hline $\begin{array}{l}\text { Morphol } \\
\text { ogy }\end{array}$ & & & & & & & & & & & & & & & & & & \\
\hline $\begin{array}{l}\text { Gram's } \\
\text { Reactio } \\
\text { n }\end{array}$ & $\begin{array}{l}+\mathrm{v} \\
\mathrm{e}\end{array}$ & $+\mathrm{ve}$ & $\begin{array}{l}+\mathrm{v} \\
\mathrm{e}\end{array}$ & $\begin{array}{l}+\mathrm{v} \\
\mathrm{e}\end{array}$ & $+\mathrm{ve}$ & $+\mathrm{ve}$ & $+\mathrm{ve}$ & $+\mathrm{ve}$ & $\begin{array}{l}+\mathrm{v} \\
\mathrm{e}\end{array}$ & $+\mathrm{ve}$ & $+\mathrm{ve}$ & $+\mathrm{ve}$ & $+\mathrm{ve}$ & $+\mathrm{ve}$ & $+\mathrm{ve}$ & $+\mathrm{ve}$ & $+\mathrm{ve}$ & $+\mathrm{ve}$ \\
\hline $\begin{array}{l}\text { Cellular } \\
\text { Shape }\end{array}$ & rod & rod & rod & rod & rod & rod & rod & rod & rod & rod & rod & rod & rod & rod & rod & rod & rod & rod \\
\hline $\begin{array}{l}\text { Bioche } \\
\text { mical } \\
\text { Charact } \\
\text { eristics }\end{array}$ & & & & & & & & & & & & & & & & & & \\
\hline $\begin{array}{l}\text { Acid } \\
\text { fast }\end{array}$ & & & & & & & $+\mathrm{ve}$ & -ve & & & & & & & & & $+\mathrm{ve}$ & \\
\hline Catalase & $\begin{array}{l}+\mathrm{v} \\
\mathrm{e}\end{array}$ & $+\mathrm{ve}$ & $\begin{array}{l}+\mathrm{v} \\
\mathrm{e}\end{array}$ & $\begin{array}{l}+\mathrm{v} \\
\mathrm{e}\end{array}$ & $+\mathrm{ve}$ & $+\mathrm{ve}$ & $+\mathrm{ve}$ & $-\mathrm{ve}$ & $\begin{array}{l}+\mathrm{v} \\
\mathrm{e}\end{array}$ & $+\mathrm{ve}$ & $+\mathrm{ve}$ & $+\mathrm{ve}$ & $+\mathrm{ve}$ & $+\mathrm{ve}$ & $+\mathrm{ve}$ & $+\mathrm{ve}$ & $+\mathrm{ve}$ & $+\mathrm{ve}$ \\
\hline Oxidase & $\begin{array}{l}+\mathrm{v} \\
\mathrm{e}\end{array}$ & $-\mathrm{ve}$ & $-\mathrm{ve}$ & -ve & $-\mathrm{ve}$ & $-\mathrm{ve}$ & $-\mathrm{ve}$ & $+\mathrm{ve}$ & -ve & $-\mathrm{ve}$ & $-\mathrm{ve}$ & $-\mathrm{ve}$ & $-\mathrm{ve}$ & $-\mathrm{ve}$ & $-\mathrm{ve}$ & $-\mathrm{ve}$ & -ve & $-\mathrm{ve}$ \\
\hline $\begin{array}{l}\text { Spore } \\
\text { formatio } \\
\mathrm{n}\end{array}$ & & & & -ve & & & -ve & -ve & & & & & & & & & -ve & \\
\hline $\begin{array}{l}\text { Starch } \\
\text { hydrolys } \\
\text { is }\end{array}$ & $\begin{array}{l}+\mathrm{v} \\
\mathrm{e}\end{array}$ & $+\mathrm{ve}$ & $\begin{array}{l}+\mathrm{v} \\
\mathrm{e}\end{array}$ & & & & & & & & & & & & & & $+\mathrm{ve}$ & \\
\hline $\begin{array}{l}\text { Manitol } \\
\text { ferment } \\
\text { ation }\end{array}$ & & & & $-\mathrm{ve}$ & $-\mathrm{ve}$ & & & $-\mathrm{ve}$ & & $+\mathrm{ve}$ & $-\mathrm{ve}$ & & & & & & & \\
\hline $\begin{array}{l}\text { Glucose } \\
\text { ferment } \\
\text { ation }\end{array}$ & & & & & & & & & & & & & & & & & & \\
\hline $\begin{array}{l}\text { Lactose } \\
\text { ferment } \\
\text { ation }\end{array}$ & & & & & & & & & -ve & & & & $+\mathrm{ve}$ & & $\begin{array}{l}+\mathrm{ve} \\
\mathrm{e}\end{array}$ & $-\mathrm{ve}$ & & $+\mathrm{ve}$ \\
\hline MR & & & $\begin{array}{l}+\mathrm{v} \\
\mathrm{e}\end{array}$ & & & $-\mathrm{ve}$ & & & $\begin{array}{l}+\mathrm{v} \\
\mathrm{e}\end{array}$ & & & & $+\mathrm{ve}$ & & $+\mathrm{ve}$ & & & -ve \\
\hline VP & -ve & -ve & -ve & & & & & & -ve & & & & -ve & & $+\mathrm{ve}$ & & & $+\mathrm{ve}$ \\
\hline $\begin{array}{l}\text { Citrate } \\
\text { utilizati } \\
\text { on }\end{array}$ & -ve & $+\mathrm{ve}$ & & & & & & & & & & & & & & & & \\
\hline $\begin{array}{l}\text { Yellow } \\
\text { pigment }\end{array}$ & & & & & $+\mathrm{ve}$ & & & & & & & & & & & & & \\
\hline $\begin{array}{l}\text { Novobio } \\
\text { cine }\end{array}$ & & & & & & & & & & $+\mathrm{ve}$ & & $-\mathrm{ve}$ & & & & & & \\
\hline
\end{tabular}

Table 4.1:-Phenotypic identities of bacteria isolated from hypersaline water body of Lagos, Nigeria

Table 4.1(contd.):-

\begin{tabular}{|c|c|c|c|c|c|c|c|c|c|c|c|c|c|c|c|c|c|c|}
\hline Characters & & & & & & & & & & & & & & & & & & \\
\hline Culture & 1 & 2 & 3 & 4 & 5 & 6 & 7 & 8 & 9 & 10 & 11 & 12 & 13 & 14 & 15 & 16 & 17 & 18 \\
\hline $\begin{array}{l}\text { Biochemical } \\
\text { Tests (contd.) }\end{array}$ & & & & & & & & & & & & & & & & & & \\
\hline $\begin{array}{l}\text { Sorbitol } \\
\text { fermentation }\end{array}$ & & & & & & & & & & & & & & & & & & $\begin{array}{l}- \\
\text { ve }\end{array}$ \\
\hline Motility & & & & & & & & & $\begin{array}{l}+\mathrm{v} \\
\mathrm{e}\end{array}$ & & & & $\begin{array}{l}- \\
\text { ve }\end{array}$ & & & & & \\
\hline Indole & & & & & & & & & -ve & & & & $\begin{array}{l}- \\
\text { ve }\end{array}$ & & & & & \\
\hline
\end{tabular}




\begin{tabular}{|c|c|c|c|c|c|c|c|c|c|c|c|c|c|c|c|c|c|c|}
\hline $\begin{array}{l}\text { Lysine } \\
\text { decarboxylas } \\
\text { e }\end{array}$ & & & & & & & & & & & & & & & & & & \\
\hline Pigmentation & & & & & & & & & $\begin{array}{l}+\mathrm{v} \\
\mathrm{e}\end{array}$ & & & & & & & & & \\
\hline Urease & & & & & & & & & $-\mathrm{ve}$ & & & & & & & $\begin{array}{l}- \\
\text { ve }\end{array}$ & & \\
\hline $\begin{array}{l}\text { Orthinine } \\
\text { decarboxylas } \\
\text { e }\end{array}$ & & & & & & & & & & & & & & & & $\begin{array}{l}- \\
\text { ve }\end{array}$ & & \\
\hline $\begin{array}{l}\text { Hydrogen } \\
\text { sulphide }\end{array}$ & & & & & & & & & $-\mathrm{ve}$ & & & & - & & & & & \\
\hline Coagulase & & & & & & & & & & $\begin{array}{l}+\mathrm{ev} \\
\mathrm{e}\end{array}$ & $\begin{array}{l}- \\
\text { ve }\end{array}$ & $\begin{array}{l}- \\
\text { ve }\end{array}$ & & & & & & \\
\hline $\begin{array}{l}\text { Probable } \\
\text { bacteria }\end{array}$ & $\begin{array}{c}0 \\
0 \\
0 \\
0 \\
0 \\
0\end{array}$ & 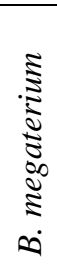 & 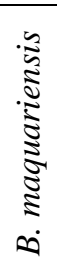 & 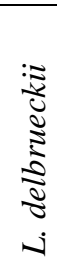 & 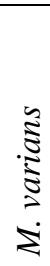 & 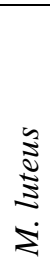 & 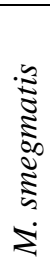 & 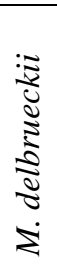 & 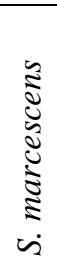 & 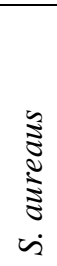 & 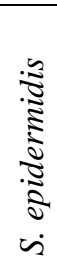 & 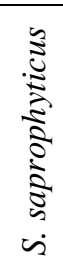 & 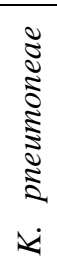 & 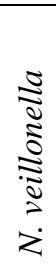 & 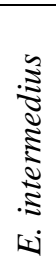 & 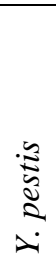 & 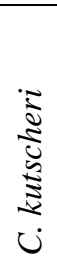 & 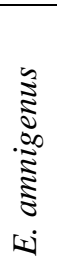 \\
\hline
\end{tabular}

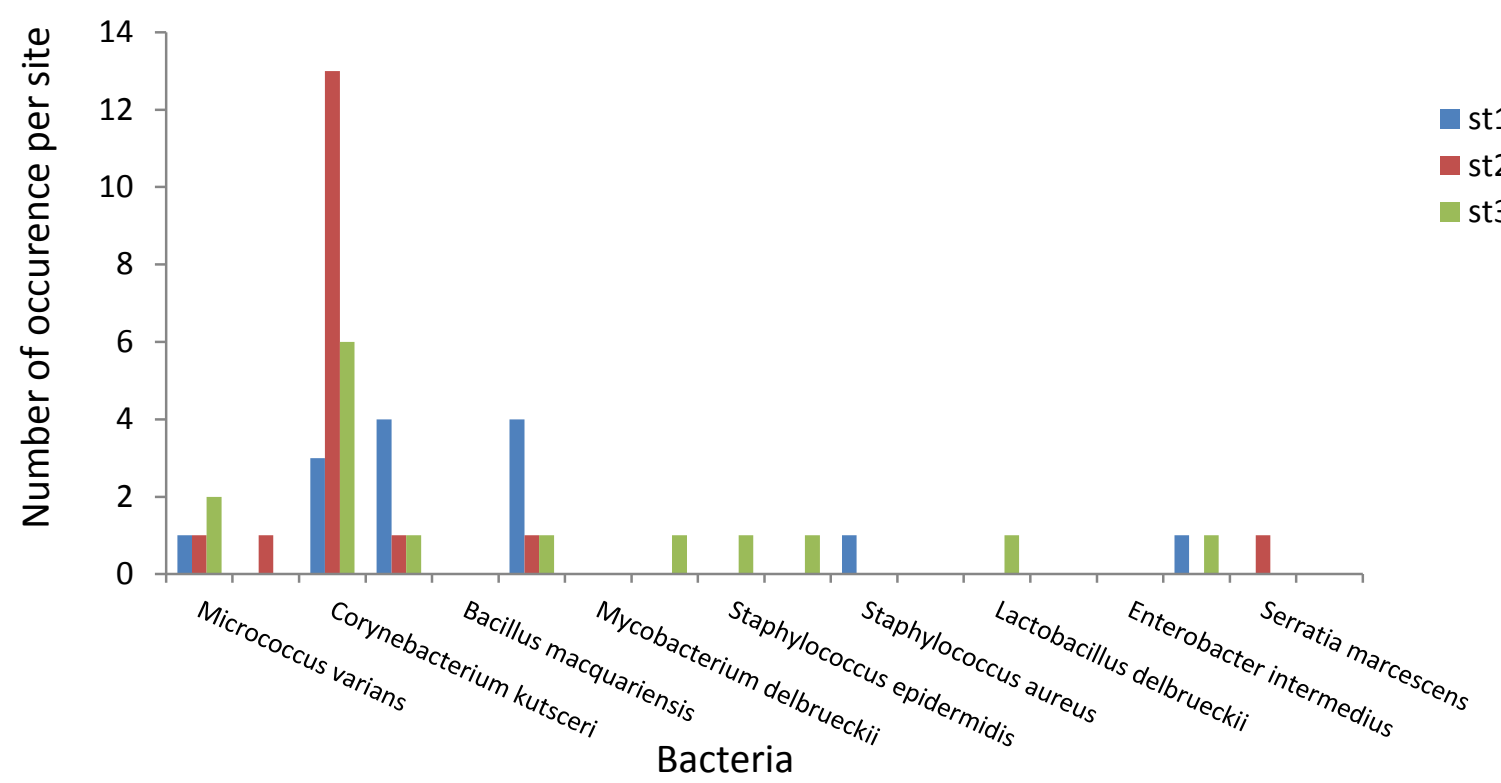

Figure 4.2:-Distribution of bacteria isolated from $0-0.07 \mathrm{~m}$ (surface) of hypersaline water bodies of Lagos, Nigeria. Legend.

$\mathrm{St} 1=$ latitude $6.35^{\circ} \mathrm{N}$ longitude $3.28^{\circ} \mathrm{E} ; \mathrm{St} 2=$ latitude $6.35^{\circ} \mathrm{N}$ longitude $3.40^{\circ} \mathrm{E}$;

$\mathrm{St} 3=$ latitude $6.36^{\circ} \mathrm{N}$ longitude $3.47^{\circ} \mathrm{E}$

Bacterial loads from each other at the three locations were non-significantly different $(\mathrm{p}<0.05)$. Corynebacterium kutsceri as the most frequently occurred (13 times) bacterium in location St2 and 6 times in site 3. This was followed by Bacillus badius and B. megaterium that occurred 4 times each in St1, but in St2 and St3 Bacillus badius and B. megaterium occurred 1 time each. The occurrence of Micrococcus varians was twice in St3, once in St 1 and St2 respectively. Micrococcus luteus from St2, Mycobacterium smegmatis from St3, S. epidermidis and S. saprophyticus also obtained from St3 including and S. aureus from St1 all occurred once. Lactobacillus delbrueckii and Enterobacter amnigenus including Serratia marcescens all obtained from St1 and St3 occurred once each. 
Howbeit, Mycobacteria delbrueckii, Klebsiella pneumonieae subsp pneumonieae, Neisseria veillonella and Yersinia pestis were not isolated from 0-0.07 $\mathrm{m}$ of the three locations sampled.

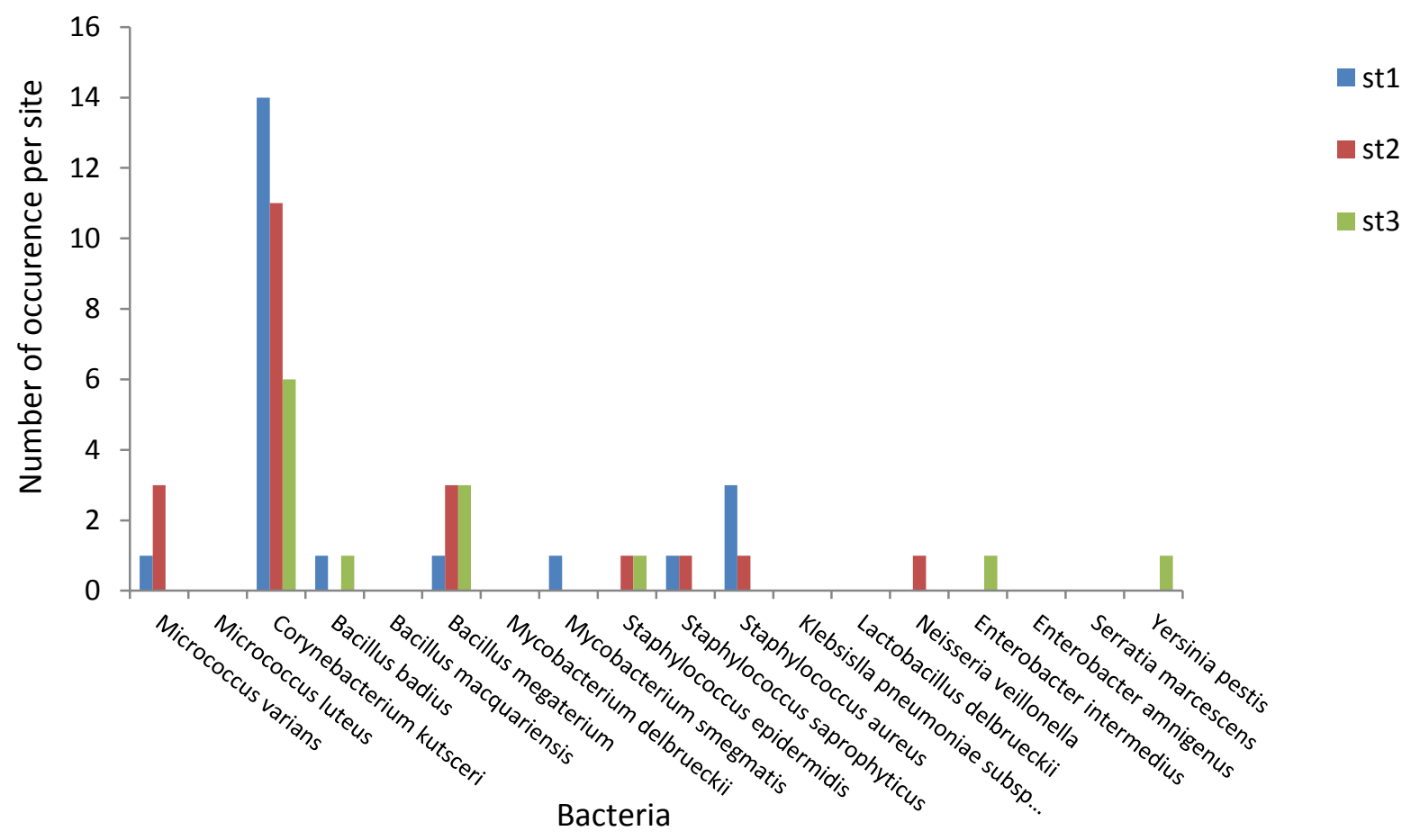

Figure 4.2.1:-Distribution of bacteria isolated from 50 meters below (middle) surface of hypersaline water bodies of Legend. Lagos, Nigeria.

St $1=$ latitude $6.35^{\circ} \mathrm{N}$ longitude $3.28^{\circ} \mathrm{E} ; \mathrm{St} 2=$ latitude $6.35^{\circ} \mathrm{N}$ longitude $3.40^{\circ} \mathrm{E}$;

$\mathrm{St} 3=$ latitude $6.36^{\circ}$ Nlongitude $3.47^{\circ} \mathrm{E}$

The bacterial isolates distribution from 50 meters below surface water shows Corynebacterium kutsceri isolated from St1, St2 and St3's occurrences of 14, 11 and 6 times consecutively. This bacterium is followed by $B$. megaterium from St1, St2 and St3 occurring 4, 2 and 4 times consecutively as well. B. badius also from St1, St2 and St3 occurred in the order of 2, 2 and 1 times occurrence. Micrococcus varians and S. aureus obtained from St1 and St2 registered their occurrence with 1, 3 and 3, 1 respectively. Mycobacterium smegmatis isolated from St1, S. epidermidis from St1 and St3, including $S$. saprophyticus isolated from St1 and St2 all occurred once. However, Micrococcus luteus, B. macquariensis, M. delbrueckii, Klebsiella Pneumonieae subsp. Pneumonieae, Lactobacillus delbrueckii and Enterobacter amnigenus, Neisseria veillonella including Serratia marcescens were not isolated from St1, St2 and St3 50 meter depth below the sampled hypersaline surface water of Lagos, Nigeria. 


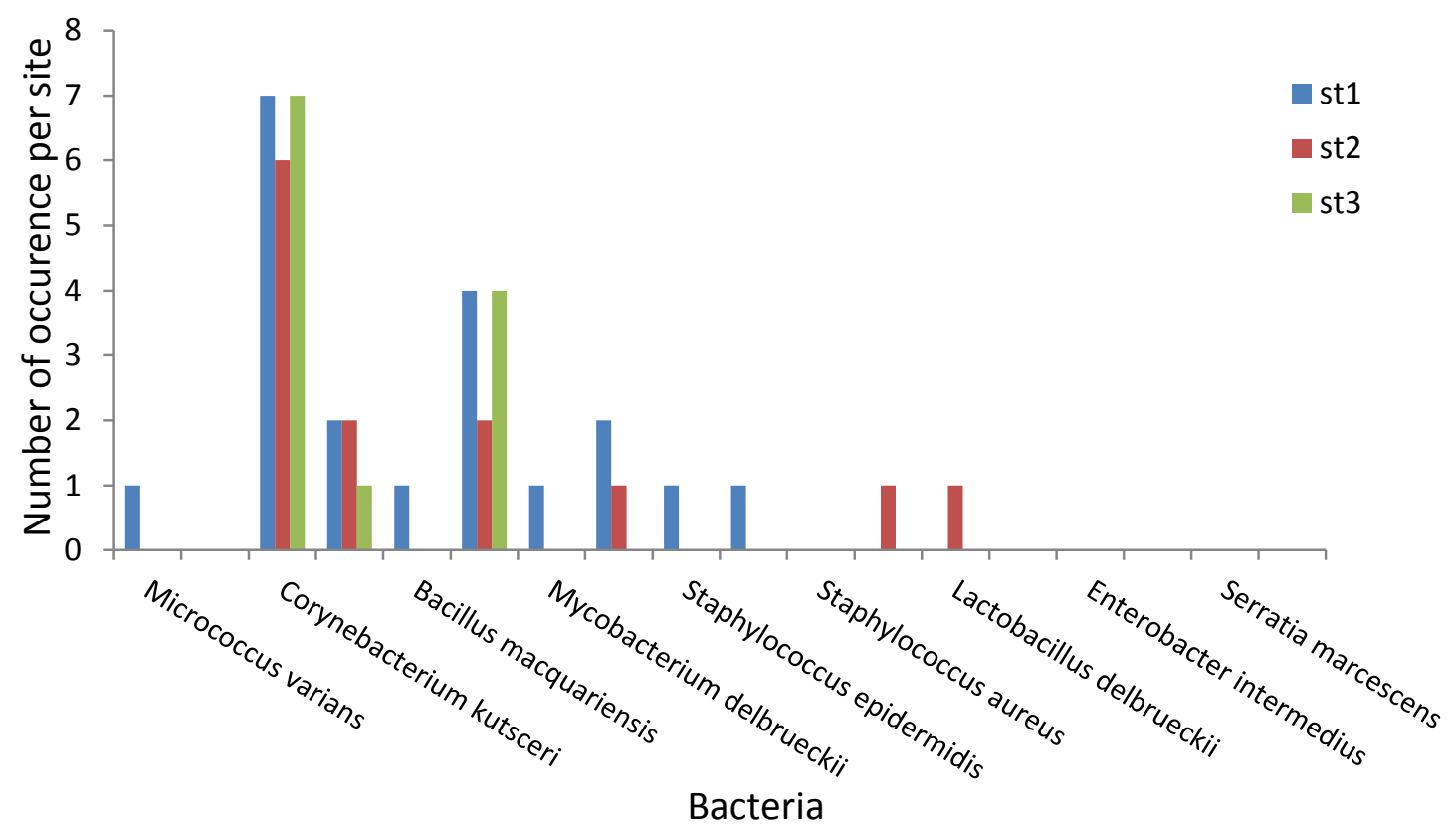

Figure 4.2.2:-Distribution of bacteria isolated from 100 meters below (bottom) surface of hypersaline water bodies of Lagos State, Nigeria.

Legend.

$\mathrm{St} 1=$ latitude $6.35^{\circ} \mathrm{N}$ longitude $3.28^{\circ} \mathrm{E} ; \mathrm{St} 2=$ latitude $6.35^{\circ} \mathrm{N}$ longitude $3.40^{\circ} \mathrm{E}$;

$\mathrm{St} 3=$ latitude $6.36^{\circ} \mathrm{N}$ longitude $3.47^{\circ} \mathrm{E}$

The distribution of bacteria isolated from 100 meters below hypersaline water surface of Lagos, Nigeria water bodies indicates the predominant occurrence of Corynebacterium kutsceri from St1, St2 and St3 with 7, 6 and 7 times consecutively, this is followed by B. megaterium from the same locations with the occurrence of 4,2 and 4 times. B. badius from St1, St2 and St3 all occurred in the order of 2, 2 and 1 times respectively. Also, Micrococcus varians, B. macquariensis, Mycobacteria delbrueckii, S. epidermidis and S. saprophyticus that are all obtained from ST1 occurred once each. Klebsiella pneumonieae subsp. Pneumonieae and Lactobacillus delbrueckii bacteria that are also obtained from St2 occurred once each. Howbeit, M. luteus, Staph. aureus, Neisseria veillonella, E. intermedius and E. amnigenus, Serratia marcescens and Yersinia pestis were not isolated from St1, St2 and St3 at the depths of 100 meter below the hypersaline water body of Lagos, Nigeria samples. 


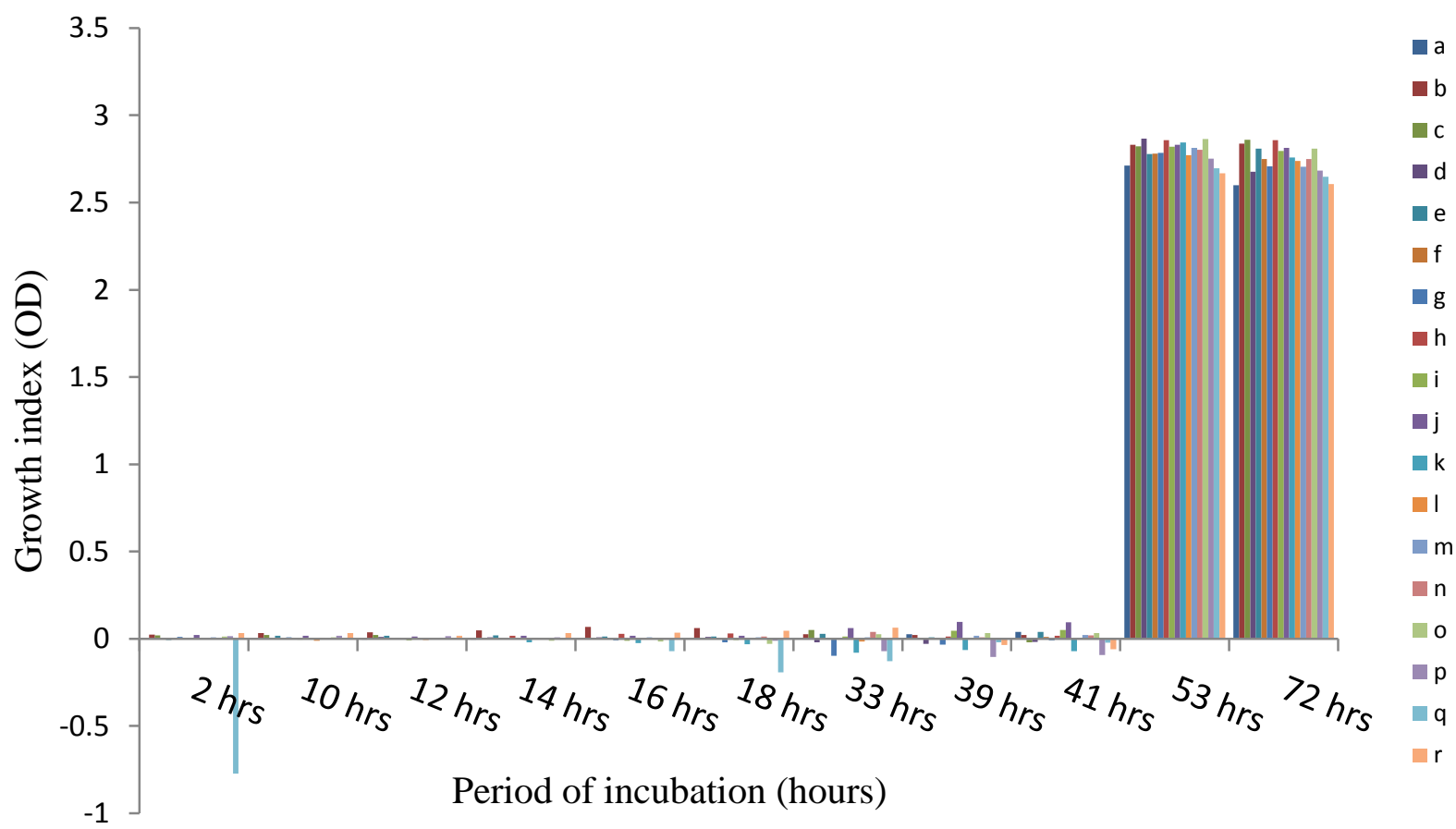

Figure 4.2.3:-The effects of 3\% salt concentration on the growth of bacteria isolated from Lagos, Nigeria hypersaline water body.

Legend:

$a=$ Yersinia pestis; $b=$ Bacillus badius; $c=$ Corynebacterium kutsceri; $d=$ Neiserra veilloneilla; $e=$ Bacillus megaterium; $\mathrm{f}=$ Enterobacter intermedius; $\mathrm{g}=$ Klebsiella pneumonia subsp pneumoniae; $\mathrm{h}=$ Enterobacter amnigenus; $\mathrm{i}=$ Staphylococcus epidermidis; $\mathrm{j}=$ Micrococcus luteus; $\mathrm{k}=$ Staphylococcus aureus; $\mathrm{l}=$ Micrococcus varians; $\mathrm{m}=$ Mycobacterium smegmatids; $\mathrm{n}=$ Staphylococcus saprophyticus; $\mathrm{o}=$ Mycobacterium delbrueckii; $\mathrm{p}=\mathrm{Bacillus}$ megaterium; q=Lactobacillus delbrueckii; r=Serratia marcescens;

Figure shows the effect of 3\% (w/v) salt on bacteria isolated from Lagos, Nigerian hypersaline water body. There was no significant $(\mathrm{p}<0.05)$ increase in the isolated bacteria growth before 41 hours of incubation. However, Lactobacillus delbrueckii among the other bacteria showed a notable decline in growth (OD - 0.77) after 2 hours of incubation. The highest growth (OD of 2.87) was recorded for Neisseria veillonella at 53 hours of incubation but, declined at 72 hours to OD 2.68. The graph generally showed that the highest growth for many of the bacterial was obtained at 53 hours of incubation before.

Table 4.4:-Producing polyhydroxylalkanoate ability of bacteria isolated from the hypersaline water body in Lagos State, Nigeria

\begin{tabular}{|l|l|l|}
\hline & Number of bacteria & Percentage number of bacterial \\
\hline Total bacterial isolates obtained & 190 & $100 \%$ \\
\hline Positive PHA potential bacterial isolates & 119 & $66.7 \%$ \\
\hline Negative PHA potential bacterial isolates & 71 & $37.4 \%$ \\
\hline
\end{tabular}

Table 4.4 shows the positive PHA and negative PHA producing potentials of bacteria isolated from hypersaline water bodies of Lagos, Nigeria water body. A total of 190 bacterial were isolated from this research and 119 $(66.7 \%)$ tested positive for PHA producing potential with the induction of glucose at $2 \%$ in minimal salt medium. 
Physicochemical analysis of physical parameters of hypersaline water body sampled from Lagos, Nigeria.

Table 4.5:-Physical characteristics of hypersaline water body in Lagos, Nigeria sampled sites for PHA bacterial isolates

\begin{tabular}{|c|c|c|c|c|c|c|c|c|c|c|}
\hline \multicolumn{11}{|c|}{ Location } \\
\hline & & \multicolumn{3}{|c|}{ 0-0.07 $\mathrm{m}$ water surface } & \multicolumn{3}{|c|}{$50 \mathrm{~m}$ below water surface } & \multicolumn{3}{|c|}{$100 \mathrm{~m}$ below water surface } \\
\hline \multicolumn{2}{|c|}{ Parameters } & St1 & St2 & St3 & St1 & St2 & St3 & St1 & St2 & St3 \\
\hline & $\begin{array}{l}\text { Temper } \\
\text { aure } \\
\left({ }^{\circ} \mathrm{C}\right)\end{array}$ & $\begin{array}{l}26.79 \pm 0.0 \\
5\end{array}$ & $\begin{array}{l}27.71 \pm 0 \\
.07\end{array}$ & $\begin{array}{l}27.56 \pm 0 \\
.03\end{array}$ & $\begin{array}{l}28.04 \pm 0 \\
.04\end{array}$ & $\begin{array}{l}23.4 \pm 0 . \\
05\end{array}$ & $\begin{array}{l}26.55 \pm 0 \\
.04\end{array}$ & $\begin{array}{l}27.54 \pm 0 \\
.04\end{array}$ & $\begin{array}{l}27.04 \pm 0 \\
.11\end{array}$ & $\begin{array}{l}27.29 \pm 0 . \\
08\end{array}$ \\
\hline & pH & $\begin{array}{l}7.88 \\
0.02\end{array}$ & $\begin{array}{l}7.96 \\
0.05\end{array}$ & $\begin{array}{l}7.89 \pm 0 \\
22\end{array}$ & $\begin{array}{l}7.78 \pm 0 . \\
55\end{array}$ & $\begin{array}{l}7.90 \pm 0 . \\
22\end{array}$ & $\begin{array}{l}7.91 \pm 0 . \\
078\end{array}$ & $\begin{array}{l}7.91 \pm 0 . \\
08\end{array}$ & $\begin{array}{l}7.70 \pm 0 . \\
067\end{array}$ & $\begin{array}{l}7.78 \pm 0.1 \\
4\end{array}$ \\
\hline & $\begin{array}{l}\text { Turbidit } \\
\text { y (NTU) }\end{array}$ & $\begin{array}{l}0.255 \pm 0.0 \\
4\end{array}$ & $\begin{array}{l}0.166 \pm 0 \\
.07\end{array}$ & $\begin{array}{l}0.303 \pm 0 \\
.03\end{array}$ & $\begin{array}{l}37.4 \pm 0 . \\
04\end{array}$ & $\begin{array}{l}17.9 \pm 0 . \\
05\end{array}$ & $\begin{array}{l}0.863 \pm 0 \\
.04\end{array}$ & $\begin{array}{l}36.4 \pm 0 . \\
04\end{array}$ & $\begin{array}{l}8.92 \pm 0 . \\
11\end{array}$ & $\begin{array}{l}0.933 \pm 0 . \\
08\end{array}$ \\
\hline & $\begin{array}{l}\text { Conduct } \\
\text { ivity } \\
(\mu \mathrm{S} / \mathrm{cm})\end{array}$ & $\begin{array}{l}39000 \pm 74 \\
.56\end{array}$ & $\begin{array}{l}38900 \pm \\
231.92\end{array}$ & $\begin{array}{l}37700 \pm \\
380.83\end{array}$ & $\begin{array}{l}41600 \pm \\
498.67\end{array}$ & $\begin{array}{l}38700 \pm \\
941.55\end{array}$ & $\begin{array}{l}37300 \pm \\
462.97\end{array}$ & $\begin{array}{l}43100 \pm \\
731.20\end{array}$ & $\begin{array}{l}43500 \pm \\
814.84\end{array}$ & $\begin{array}{l}42000 \pm 2 \\
46.07\end{array}$ \\
\hline & $\begin{array}{l}\text { Total } \\
\text { suspend } \\
\text { ed solids } \\
(\mathrm{mg} / \mathrm{L})\end{array}$ & $2 \pm 1.24$ & $1 \pm 0.81$ & $0 \pm 0$ & & $\begin{array}{l}48 \pm 22.7 \\
6\end{array}$ & $21 \pm 9.93$ & $\begin{array}{l}8 \pm 2.624 \\
67\end{array}$ & $37 \pm 2.16$ & $9 \pm 2.44$ \\
\hline$\frac{\vec{U}}{\sqrt[0]{n}}$ & \begin{tabular}{|l|} 
Total \\
dissolve \\
d solids \\
$(\mathrm{mg} / \mathrm{L})$
\end{tabular} & $\begin{array}{l}21250 \pm 92 \\
29.16\end{array}$ & $\begin{array}{l}21390 \pm \\
504.22\end{array}$ & $\begin{array}{l}20730 \pm \\
196.90\end{array}$ & $\begin{array}{l}22880 \pm \\
816.02\end{array}$ & $\begin{array}{l}21200 \pm \\
889.30\end{array}$ & $\begin{array}{l}20500 \pm \\
530.07\end{array}$ & $\begin{array}{l}23705 \pm \\
225.03\end{array}$ & $\begin{array}{l}23900 \pm \\
94.07\end{array}$ & $\begin{array}{l}23100 \pm 2 \\
056.42\end{array}$ \\
\hline
\end{tabular}

Legend.

St $1=$ latitude $6.35^{\circ} \mathrm{N}$ longitude $3.28^{\circ} \mathrm{E} ; \mathrm{St} 2=$ latitude $6.35^{\circ} \mathrm{N}$ longitude $3.40^{\circ} \mathrm{E}$;

$\mathrm{St} 3=$ latitude $6.36^{\circ} \mathrm{N}$ longitude $3.47^{\circ} \mathrm{E}$

Physicochemical analysis of chemical parameters of hypersaline water sampled from Lagos, Nigeria.

Table 4.5.1:-Chemical characteristics of hypersaline water body in Lagos, Nigeria sampled sites for PHA bacterial isolates

\begin{tabular}{|c|c|c|c|c|c|c|c|c|c|c|}
\hline \multirow{3}{*}{\multicolumn{2}{|c|}{ Parameters }} & \multicolumn{9}{|l|}{ Location } \\
\hline & & \multicolumn{3}{|c|}{$0-0.07 \mathrm{~m}$ water surface } & \multicolumn{3}{|c|}{$50 \mathrm{~m}$ below water surface } & \multicolumn{3}{|c|}{$100 \mathrm{~m}$ below water surface } \\
\hline & & St1 & St2 & St3 & St1 & St2 & St3 & St1 & $\mathrm{St} 2$ & St3 \\
\hline \multirow{6}{*}{ 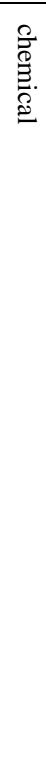 } & $\begin{array}{l}\text { Total } \\
\text { acidity } \\
(\mathrm{mg} / \mathrm{L})\end{array}$ & $40 \pm 8.16$ & $90 \pm 21.20$ & $130 \pm 14.14$ & $50 \pm 8.16$ & $10 \pm 0.00$ & $80 \pm 16.33$ & $40 \pm 0.0$ & $60 \pm 16.33$ & $70 \pm 8.16$ \\
\hline & $\begin{array}{l}\text { Chlorid } \\
\text { e } \\
(\mathrm{mg} / \mathrm{L})\end{array}$ & $\begin{array}{l}15240 \pm 21 \\
4.17\end{array}$ & $\begin{array}{l}15670 \pm 96 \\
.26\end{array}$ & $\begin{array}{l}16760 \pm 13 \\
4.91\end{array}$ & $\begin{array}{l}17190 \pm 39 \\
2.26\end{array}$ & $\begin{array}{l}17900 \pm 81 \\
65\end{array}$ & $\begin{array}{l}15240 \pm 17 \\
6.64\end{array}$ & $\begin{array}{l}17720 \pm 216 \\
49\end{array}$ & $\begin{array}{l}17930 \pm 72 \\
.57\end{array}$ & $\begin{array}{l}14880 \pm 20 \\
0.5\end{array}$ \\
\hline & $\begin{array}{l}\text { Nitrate } \\
(\mathrm{mg} / \mathrm{L})\end{array}$ & $20.4 \pm 0.62$ & $21.5 \pm 0.85$ & $16.5 \pm 0.14$ & $7.7 \pm 0.216$ & $7.6 \pm 0.37$ & $5.2 \pm 0.35$ & $9.4 \pm 0.637$ & $14 \pm 0.16$ & $3.7 \pm 0.24$ \\
\hline & $\begin{array}{l}\text { Phosph } \\
\text { ate } \\
(\mathrm{mg} / \mathrm{L})\end{array}$ & $0.97 \pm 0.02$ & $0.86 \pm 0.05$ & $0.24 \pm 0.03$ & $\begin{array}{l}0.96 \pm 0.00 \\
8\end{array}$ & $0.74 \pm 0.03$ & $0.3 \pm 0.014$ & $0.44 \pm 0.037$ & $0.93 \pm 0.35$ & $0.18 \pm 0.02$ \\
\hline & $\begin{array}{l}\text { Sulphat } \\
\text { e } \\
(\mathrm{mg} / \mathrm{L})\end{array}$ & $\begin{array}{l}2750 \pm 66.8 \\
3\end{array}$ & $\begin{array}{l}2700 \pm 8.1 \\
65\end{array}$ & $\begin{array}{l}2770 \pm 21.6 \\
0\end{array}$ & $\begin{array}{l}2790 \pm 37.4 \\
17\end{array}$ & $\begin{array}{l}3380 \pm 42.4 \\
26\end{array}$ & $\begin{array}{l}2990 \pm 86.0 \\
2\end{array}$ & $\begin{array}{l}2950 \pm 64.80 \\
7\end{array}$ & $\begin{array}{l}3620 \pm 21 \\
60\end{array}$ & $\begin{array}{l}3220 \pm 35.5 \\
9\end{array}$ \\
\hline & $\begin{array}{l}\text { Chemic } \\
\text { al } \\
\text { Oxygen } \\
\text { Deman } \\
\text { d } \\
(\mathrm{mg} / \mathrm{L})\end{array}$ & $4.21 \pm 8.28$ & $\begin{array}{l}1986 \pm 4.9 \\
6\end{array}$ & $\begin{array}{l}2174 \pm 17.5 \\
6\end{array}$ & $\begin{array}{l}2239 \pm 28.8 \\
56\end{array}$ & $2203 \pm 70.8$ & $\begin{array}{l}2737 \pm 51.6 \\
5\end{array}$ & $\begin{array}{l}1984 \pm 47.63 \\
3\end{array}$ & $\begin{array}{l}2096 \pm 26 . \\
73\end{array}$ & $\begin{array}{l}3699 \pm 173 \\
73\end{array}$ \\
\hline
\end{tabular}




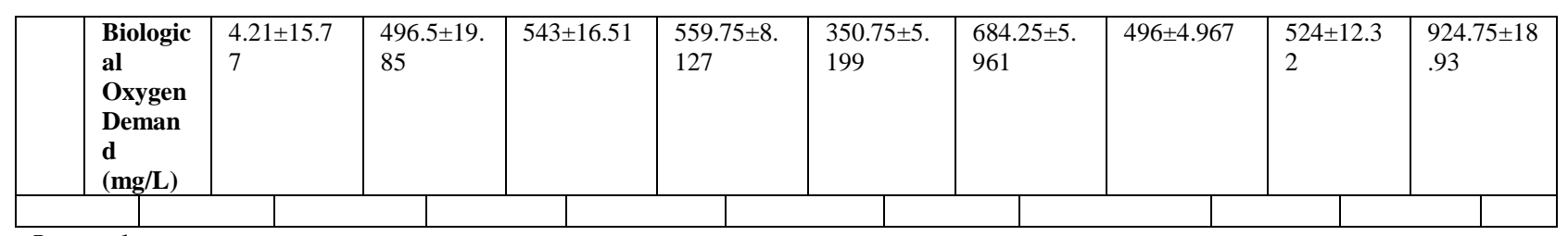

Legend.

St1 = latitude $6.35^{\circ} \mathrm{N}$ longitude $3.28^{\circ} \mathrm{E} ; \mathrm{St} 2=$ latitude $6.35^{\circ} \mathrm{N}$ longitude $3.40^{\circ} \mathrm{E}$; St3= latitude $6.36^{\circ} \mathrm{N}$ longitude $3.47^{\circ} \mathrm{E}$.

Table 4.5 shows the physical characteristics of the hypersaline water body of Lagos, Nigeria, where $\mathrm{pH}$ ranged between $(7.70 \pm 0.067$ and $7.96 \pm 0.05)$ for $\mathrm{st} 2$ at $100 \mathrm{~m}$ below water surface and $\mathrm{st} 2$ at $0-7 \mathrm{~cm}$ water surface; Turbidity between $(0.166 \pm 0.07$ and 37.4 \pm 0.04$)$ NTU (Nephelometric unit) for $0-7 \mathrm{~cm}$ water surface in St2 and $50 \mathrm{~m}$ below water surface at St1 respectively; conductivity between (37300 4462 and $9743100 \pm 731.20) \mu \mathrm{S} / \mathrm{cm}$ for $100 \mathrm{~m}$ below water surface and $50 \mathrm{~m}$ below water surface in St1 and St3 respectively; and TDS between (20500 \pm 530 and $0723900 \pm 94.07) \mathrm{mg} / \mathrm{L}$ for $100 \mathrm{~m}$ below water surface and $50 \mathrm{~m}$ below water surface in St1 and St3 respectively.

Table 4.5.1 shows the chemical characteristics of the hypersaline water body of Lagos, Nigeria where highest and lowest parameters of total acidity $(\mathrm{mg} / \mathrm{L})$ of $130 \pm 14.14$ and $10 \pm 0.00$ records for $0-7 \mathrm{~cm}$ water surface at st3 and 50 $\mathrm{m}$ below water surface at St2 respectively. Other chemical parameters includes chloride (mg/L) $17930 \pm 72.57$ and $14880 \pm 200.5$ for $100 \mathrm{~m}$ below water surface at st 2 and $100 \mathrm{~m}$ below water surface a st 3 respectively; nitrate (mg/L) $21.5 \pm 0.85$ and $3.7 \pm 0.24$ records for $0-7 \mathrm{~cm}$ water surface and $100 \mathrm{~m}$ below water surface in St2 and St3 respectively; phosphate $(\mathrm{mg} / \mathrm{L}) \quad 0.97 \pm 0.02$ and $0.24 \pm 0.03$ obtained from $0-7 \mathrm{~cm}$ water surface in St1 and St3 respectively; sulphate $(\mathrm{mg} / \mathrm{L}) 3620 \pm 21.60$ and $2700 \pm 8.165$ records for $0-7 \mathrm{~cm}$ water surface and $100 \mathrm{~m}$ below water surface in St2 and St3 respectively; dissolved oxygen $(\mathrm{mg} / \mathrm{L}) 4.42 \pm 0.05$ and $4.08 \pm 0.043$ obtained from $0-7 \mathrm{~cm}$ water surface and $50 \mathrm{~m}$ below water surface in St2; COD (mg/L) 3699 \pm 173.73 and $4.21 \pm 8.28$ records of $0-7 \mathrm{~cm}$ water surface and $100 \mathrm{~m}$ below water surface in St1 and St3 respectively; and BOD (mg/L) 924.75 \pm 18.93 and 4.21 \pm 15.77 obtained from 0-7 cm water surface and $100 \mathrm{~m}$ below water surface in St1 and St3 respectively.

\section{Discussion:-}

There is no significant difference $(\mathrm{p}<0.05)$ in the data of bacterial distribution obtained in shown in figure 1of this research, and this agrees with the findings that $100 \mathrm{~m}$ depth is not enough for the spatial difference when considering other factors such as dissolved oxygen, photic effect, period of sample and frequent waves experienced by the water body (Breitburg, et al., 2018; Grasshoff et al., 2009; Tissot and Welte, 2013). Figure 4.2, 4.2.1 and 4.2.3 reveals that Corynebacterium kutscheri is widely distributed organism found across all sites and depths sampled in this research. It also shows that there is no significant difference $(p<0.05)$ in the occurrence of this same bacterial isolates between $0-0.07 \mathrm{~m}$ and $50 \mathrm{~m}$ below surface of the water but reveals tremendous difference between the aforementioned depths with that of $100 \mathrm{~m}$ below water surface $(\mathrm{p}<0.05)$. This may be as a result of the lower dissolved oxygen recorded at $100 \mathrm{~m}$ below water surface compared to the values that of $0-0.07 \mathrm{~m}$ and $50 \mathrm{~m}$ below surface water which has no significant values $(\mathrm{p}<0.05)$. Thus dissolved oxygen may be said to affect the growth of Corynebacterium kutscheri. This aforementioned result is in agreement with the characteristics of Corynebacterium sp. as salt tolerant like Micrococcus, Bacillus species as well as Staphylococcus species (Barksdale et al., 1981; Denis et al., 2001; Anihouvi et al., 2007).

Figure 4.3 shows the initiation of exponential period at 53 hours from the effects of $3 \%$ salt on the growth of bacteria isolates from Lagos, Nigeria hypersaline water body. Hence, apart from the adjustment of bacterial isolates to temperature, osmotic pressure, atmospheric pressure, $\mathrm{pH}$, and moisture availability among other environmental factors (Kaye and Baross, 2004), the bacterial isolates displayed the characteristic of accumulating enough salt concentration ( known as lag period of which may also be term period of growth adjustment) in order to initiate the proliferation (cellular multiplication), and this may be because their genetic makeup may require sodium chloride or salt for growth (Elabed et al., 2019). Figure 4.3 also displayed the 'salt shock' experienced of Lactobacillus delbrueckii where the initial inoculum size was seen to be significantly decreased ( $\mathrm{p} \geq 0.05)$ before 53 hour after culture when it fully recovered. Thus, the acclimatizing period of over 52 hours of accumulation may be required for $3 \%$ of salts $(\mathrm{NaCl})$ concentration for Lactobacillus delbrueckii for the initiation of proliferation as observed in this research. Figure 4.3 clearly shows that Lactobacillus delbrueckii experienced 'salt shock' at 2 hours of incubation before progressive recovery at 41 hours after incubation. 
All eighteen (18) bacterial isolated conventionally are identified as Bacillus species 4 (22.22\%) species, Corynebacterium specie, $1(0.06 \%)$, Enterobacter $2(0.11 \%)$, Klebsiella $1(0.06 \%)$, and Micrococcus $2(0.11 \%)$ species. Mycobacterium also recorded $2(0.06 \%)$ species, Neisseria veillonella $1(0.06 \%)$, Staphylococcus species 3 $(0.17 \%)$ and Yersinia $1(0.06 \%)$. Hence from these bacterial isolates, Bacillus species have been predominantly known to produce PHA under different environmental conditions and carbon source (Halami, 2009). Also, Enterobacter species do accumulates PHA production (Ceyhan and Guven, 2011) even when isolated from other source but may be dependent upon the conditions as well as genetic inclination for PHA production. Corynebacterium species is another PHA producer when circumstance triggers the production. These bacteria are members of the taxonomically related genera Rhodococcus, Nocardia and Corynebacterium, and it has been discovered that $3 \mathrm{HV}$ and $3 \mathrm{HB}$ monomers present in PHA is dependent on the carbon source and Laos noted that $3 \mathrm{HV}$ is generally the major 3-hydroxyacid produced (Anderson et al, 1990).

\section{Conclusion:-}

The data available from this research hereby suggests the presence of Corynebacterium kutsceri proliferation at all the three depths and sites researched in this work, it also pointed that their population is reduced as the available concentration of dissolved oxygen decreases. C. kutsceri is a PHA producer among others viz: Micrococcus varians, M. luteus, Bacillus badius, B. macquariensis, B. megaterium, Mycobacterium delbrueckii, Mycobacterium smegmatis, Staphylococcus aureus, Staphylococcus saprophyticus, Staphylococcus epidermidis, Lactobacillus delbrueckii, Klebsiella pneumonia subsp. pneumoniae, Neisseria veillonella, Enterobacter amnigenus and Serratia'marcescens. However, only 2 bacterial isolates (Enterobacter intermedius and Yersinia pestis) from the sampled site did not test positive for PHA when induced with glucose.

\section{Acknowledgements:-}

The researchers of this article hereby acknowledge the assistance of Mr. Daramola, Felix A and Mr. Oyejide, Nicholas E of Redeemer's University, Ede, Nigeria during the laboratory sessions on biochemical tests for the bacterial identification.

\section{Funding:}

This research did not receive any specific grant from funding agencies in the public, commercial, or not-for-profit sectors.

\section{References:-}

1. Aditi, S., Souza Shalet, N., Pranesh, R., \& Katyayini, T. (2015). Microbial production of polyhydroxyalkanoates (PHA) from novel sources: a review. Int J RBS, 4, 16-28.

2. Anihouvi, V., Sakyi-Dawson, E., Ayernor, G., \& Hounhouigan, J. (2007). Microbiological changes in naturally fermented cassava fish (Pseudotolithus sp.) for lanhouin production. International journal of food microbiology, 116(2), 287-291.

3. Barksdale, L., Linder, R., Sulea, I. T., \& Pollice, M. (1981). Phospholipase D activity of Corynebacterium pseudotuberculosis (Corynebacterium ovis) and Corynebacterium ulcerans, a distinctive marker within the genus Corynebacterium. Journal of clinical microbiology, 13(2), 335-343.

4. Bergey, D. H., Breed, R. S., Murray, E. G. D., \& Hitchens, A. P. (1939). Manual of determinative bacteriology. Manual of determinative bacteriology. Fifth Edn.

5. Board, N. (2004). Polymers and Plastics Technology Handbook: ASIA PACIFIC BUSINESS PRESS Inc.

6. Breitburg, D., Levin, L. A., Oschlies, A., Grégoire, M., Chavez, F. P., Conley, D. J., et al. (2018). Declining oxygen in the global ocean and coastal waters. Science, 359(6371), eaam7240.

7. Bugnicourt, E., Cinelli, P., Lazzeri, A., \& Alvarez, V. A. (2014). Polyhydroxyalkanoate (PHA): Review of synthesis, characteristics, processing and potential applications in packaging.

8. Ceyhan, N., \& Ozdemir, G. (2011). Poly--hydroxybutyrate (PHB) production from domestic wastewater using Enterobacter aerogenes 12Bi strain. African Journal of Microbiology Research, 5(6), 690-702.

9. Chao, M. C., Kieser, K. J., Minami, S., Mavrici, D., Aldridge, B. B., Fortune, S. M., et al. (2013). Protein complexes and proteolytic activation of the cell wall hydrolase RipA regulate septal resolution in mycobacteria. PLoS pathogens, 9(2), e1003197.

10. DasSarma, S., \& DasSarma, P. (2012). Halophiles: Wiley Online Library.

11. DasSarma, S. L., Capes, M. D., DasSarma, P., \& DasSarma, S. (2010). HaloWeb: the haloarchaeal genomes database. Saline Systems, 6(1), 12. 
12. de Lourdes Moreno, M., Pérez, D., García, M. T., \& Mellado, E. (2013). Halophilic bacteria as a source of novel hydrolytic enzymes. Life, 3(1), 38-51.

13. Denis, C., Gueguen, M., Henry, E., \& Levert, D. (2001). New media for the numeration of cheese surface bacteria. Le Lait, 81(3), 365-379.

14. Elabed, H., González-Tortuero, E., Ibacache-Quiroga, C., Bakhrouf, A., Johnston, P., Gaddour, K., ... \& Rodríguez-Rojas, A. (2019). Seawater salt-trapped Pseudomonas aeruginosa survives for years and gets primed for salinity tolerance. BMC Microbiology, 19(1), 142.

15. Grasshoff, K., Kremling, K., \& Ehrhardt, M. (2009). Methods of seawater analysis: John Wiley \& Sons.

16. Ibtisam, Kamal and Allaf Karim. "Review Paper (SS-1) Impact of global warming, Military conflicts and industrial processing wastes on environment." (2012).

17. Halami, P. M. (2008). Production of polyhydroxyalkanoate from starch by the native isolate Bacillus cereus CFR06. World Journal of Microbiology and Biotechnology, 24(6), 805-812.

18. Hall, C. (1981). Polymer Materials and their Technology Polymer Materials (pp. 141-183): Springer.

19. Kaye, J. Z., \& Baross, J. A. (2004). Synchronous effects of temperature, hydrostatic pressure, and salinity on growth, phospholipid profiles, and protein patterns of four Halomonas species isolated from deep-sea hydrothermal-vent and sea surface environments. Appl. Environ. Microbiol., 70(10), 6220-6229.

20. Khanna, S., \& Srivastava, A. K. (2005). Recent advances in microbial polyhydroxyalkanoates. Process biochemistry, 40(2), 607-619.

21. Kosseva, Maria R, and Colin Webb. Food Industry Wastes: Assessment and Recuperation of Commodities. , 2013. Internet resource.

22. Kushner, D. J. (1978). Microbial life in extreme environments: Academic Press.

23. Madigan, M. T., \& Martinko, J. M. (2006). Microorganisms and microbiology. Brock biology of microorganisms. 11th ed. Upper Saddle River, New Jersey (NJ): Pearson Prentice Hall, 1-20.

24. Manikandan, P., \& Senthilkumar, P. K. (2017). On overview of saltpan halophilic bacterium.

25. Mojaveryazdia, F. S., Zainb, N. A. B. M., \& Rezaniac, S. (2013). Production of biodegradable polymers (PHA) through low cost carbon sources: green chemistry. International Journal, 4(3).

26. Naik, P. R., Raman, G., Narayanan, K. B., \& Sakthivel, N. (2008). Assessment of genetic and functional diversity of phosphate solubilizing fluorescent pseudomonads isolated from rhizospheric soil. BMC microbiology, 8(1), 230.

27. Olabisi, O., \& Adewale, K. (2016). Handbook of thermoplastics: CRC press.

28. Ollivier, B., Caumette, P., Garcia, J.-L., \& Mah, R. (1994). Anaerobic bacteria from hypersaline environments. Microbiology and molecular biology reviews, 58(1), 27-38.

29. Oren, A. (2002). Molecular ecology of extremely halophilic Archaea and Bacteria. FEMS Microbiology Ecology, 39(1), 1-7.

30. Oren, A. (2013). Life at high salt concentrations. The prokaryotes: Prokaryotic communities and ecophysiology, 421-440.

31. Parthasarathi, S., \& BALAKRISHNAN, K. (2013). Isolation, Characterization and Bioprospecting of a selected marine actinomycete.

32. Reddy, C., Ghai, R., \& Kalia, V. C. (2003). Polyhydroxyalkanoates: an overview. Bioresource Technology, 87(2), 137-146.

33. Saharan, P., Chaudhary, G. R., Mehta, S., \& Umar, A. (2014). Removal of water contaminants by iron oxide nanomaterials. Journal of nanoscience and nanotechnology, 14(1), 627-643.

34. Santini, T. C., Kerr, J. L., \& Warren, L. A. (2015). Microbially-driven strategies for bioremediation of bauxite residue. Journal of Hazardous Materials, 293, 131-157.

35. Saranya, V., \& Shenbagarathai, R. (2011). Production and characterization of PHA from recombinant E. coli harbouring phaC1 gene of indigenous Pseudomonas sp. LDC-5 using molasses. Brazilian Journal of Microbiology, 42(3), 1109-1118.

36. Tissari, P., Zumla, A., Tarkka, E., Mero, S., Savolainen, L., Vaara, M., et al. (2010). Accurate and rapid identification of bacterial species from positive blood cultures with a DNA-based microarray platform: an observational study. The Lancet, 375(9710), 224-230.

37. Tissot, B. P., and Welte, D. H. (2013). Petroleum formation and occurrence: Springer Science \& Business Media.

38. Zhang, Y., Li, X., Bartlett, D. H., and Xiao, X. (2015). Current developments in marine microbiology: highpressure biotechnology and the genetic engineering of piezophiles. Current opinion in biotechnology, 33, 157164. 